\title{
As Contribuições da Psicologia aos Ideais da Liga Brasileira de Higiene
}

\author{
Mental: Algumas Reflexões
}

\author{
Roselania Francisconi Borges* \\ Universidade Estadual de Maringá - UEM, Maringá, PR, Brasil \\ ORCID: https:/orcid.org/0000-0002-5611-5144
}

\begin{abstract}
RESUMO
A psicologia científica é um produto histórico configurado por uma diversidade teórica e metodológica que, em solo brasileiro, foi fortemente constituída no final do século XIX e início do século XX. Tendo em vista esta diversidade, este estudo faz um recorte e trata da parceria entre a Psicologia e a Liga Brasileira de Higiene Mental (LBHM), no que tange às aferições das diferenças individuais. O movimento higienista, materializado pela LBHM, exerceu forte influência sobre as práticas psicológicas as quais serviram de sustentação científica para a implantação de políticas públicas visando um padrão de normalidade, via seleção dos considerados capazes e incapazes, tanto para fatores relacionados a padrões de conduta e de comportamento, quanto para fatores relacionados a aprendizagem de conteúdos acadêmicos. Atualmente, em meio a inúmeras tentativas de implantação de pautas conservadoras nas políticas públicas, grande parte dos profissionais da Psicologia busca compreender em que os saberes psicológicos podem contribuir para ampliar avanços e evitar retrocessos. Exercitar a competência para a reflexão que a ciência psicológica proporciona pode ser uma alternativa para suplantar a histórica busca de um dado padrão de normalidade. Após mais de um século, esta ainda parece ser uma tarefa urgente e necessária para a Psicologia.
\end{abstract}

Palavras-chave: Psicologia científica, Liga Brasileira de Higiene Mental, movimento higienista, aferição das diferenças individuais.

\section{The contributions of Psychology to the ideals of the Brazilian Mental}

\section{Hygiene League: some considerations}

\begin{abstract}
Scientific psychology is a historical outcome shaped by a theoretical and methodological diversity that, nationwide, was established at the end of the XIXth century and the beginning of the XXth. Bearing said diversity in mind, this study makes a cutout and addresses the collaboration between psychology and the Brazilian Mental Hygiene League (BMHL), regarding the assessment of individual differences. The hygienist movement, materialized by
\end{abstract}


the BMHL, exercised a profound influence over psychological conducts which in turn acted as scientific support for the enforcement of public policies directed towards a normality standard, by means of selecting those considered capable and incapable, either by factors concerning conduct and behavior patterns, either by factors related to learning academic contents. Nowadays, facing countless attempts to establish conservative guidelines for public policies, the majority of psychologists strive to understand in what manner their specific knowledge is able to contribute to increase progress and avoid regression. To foster the reflection provided by scientific psychology might be an alternative to the historical pursue of a normality standard. A century past, this seems to remain an urgent and necessary task for Psychology.

Keywords: Scientific Psychology, Brazilian Mental Hygiene League, hygienist movement, assessment of individual differences.

\title{
Las Contribuciones de la Psicología a los Ideales de la Liga Brasileña de
}

\author{
Higiene Mental: Algunas Reflexiones
}

\begin{abstract}
RESUMEN
La psicología científica es un producto histórico configurado por una diversidad teórica y metodológica que, en tierras brasileñas, se constituyó con solidez a finales del siglo XIX y al comienzo del siglo XX. Con esta diversidad en mente, este ensayo hace un recorte y aborda la sociedad entre la Psicología y la Liga Brasileña de Higiene Mental (LBHM), con respecto a la evaluación de las diferencias individuales. El movimiento higienista, materializado por la LBHM, exerció fuerte influencia sobre las prácticas psicológicas que a su vez sirvieron de fundamento científico para la implantación de políticas públicas dirigidas a un patrón de normalidad, por la vía de la selección de los considerados capaces o incapaces, sea por razones de patrón de conducta y de comportamiento, sea por razones de aprendizaje de contenidos académicos. Actualmente, a medias de las numerosas tentativas de implantación de directrizes conservadoras en las políticas públicas, gran parte de los profesionales de la Psicología busca comprender de qué manera los saberes psicológicos pueden aportar para ampliar avances y evitar retrocesos. Ejercitar la competencia para la reflexión que la ciencia psicológica proporciona puede ser una alternativa para reemplazar la histórica búsqueda de un determinado patrón de normalidad. Tras más de un siglo, esta, todavía, parece ser una tarea urgente y necesaria para la Psicología.
\end{abstract}

Palabras-clave: Psicología científica, Liga Brasileña de Higiene Mental, movimiento higienista, afericción de las diferencias individuales. 
Em tempos de defesa dos princípios da inclusão enquanto bandeira de luta por direitos à saúde, educação, moradia digna, entre outros direitos sociais em geral, há um posicionamento mais ou menos delimitado por parte dos diversos saberes científicos a respeito dessa questão, visto que falar sobre inclusão é falar sobre diferenças de acesso e permanência em espaços institucionais e/ou sociais. Tal debate, em nosso entender, requer contextualização, posto que, conforme Santos (2006, p. 316), “[...] temos o direito a ser iguais sempre que a diferença nos inferioriza; temos o direito a ser diferentes sempre que a igualdade nos descaracteriza".

Trazendo esta observação para a área da Psicologia, enquanto ciência e profissão que tem como objeto de estudo e intervenção o homem como sujeito individual, em sua singularidade e, ao mesmo tempo, como ser histórico e, portanto, social, se faz necessário elucidar onde se situa o pressuposto que faz jus ao estudo e à demarcação das diferenças individuais, sejam elas voltadas ao contexto da saúde, da educação, da justiça etc. Exemplos desse aporte são os laudos psicológicos, as avaliações psicológicas na educação, os exames criminológicos, bem como outros documentos elaborados por psicólogos com a finalidade de determinar encaminhamentos e outros objetivos.

Trabalhamos com a perspectiva de que a ciência psicológica, assim como as demais ciências, é um produto histórico. Enquanto tal, configura-se a partir de demandas específicas geradas e requeridas em um dado contexto histórico. Conforme Cambaúva, Silva e Ferreira (1998, p. 208), a Psicologia é uma prática social constituída por fundamentos “[...] históricos e filosóficos que estão intimamente ligados à própria forma de o homem viver e se expressar na sociedade".

Nesse caso, ao abordar os fundamentos históricos e filosóficos da Psicologia tomamos o homem enquanto produto e produtor de sua existência e, como consequência, dos saberes científicos gestados e consolidados enquanto prática social. Segundo esse ponto de vista, as práticas psicológicas são produtos da atividade humana nascidas em determinado contexto sócio-histórico e cultural a partir de necessidades históricas. Para afiançar nosso posicionamento, nos amparamos na seguinte afirmação de Engels:

Os próprios seres humanos fazem a sua história. Porém, até o presente, não a fizeram com uma vontade comum, em conformidade com um plano geral, nem mesmo em uma dada sociedade, precisamente delimitada. Suas aspirações entrecruzam-se e, em todas essas sociedades, reina, precisamente por isso, a necessidade [grifos do autor] 
cuja extensão e forma fenomênica é o acaso [grifos do autor] (Marx \& Engels, 1968, pp. 205).

Por esta perspectiva, não há acaso na história. Há as necessidades movidas pelas relações concretas de produção e reprodução da vida levando ao desenvolvimento deste ou daquele saber sistematizado, podendo parecer, contudo, ao olhar não analítico, como obra do acaso Nesse bojo, "os projetos de psicologia como ciência", autônoma da filosofia, se configuraram no momento histórico em que as condições criadas e as demandas, configuravam o "[...] o terreno propício à ampla difusão desses projetos e à sua assimilação crescente pelo conjunto da sociedade" (Figueiredo \& Santi, 2004, p. 53).

No lastro desse entendimento, um dos importantes pressupostos das ciências naturais, aos quais a Psicologia científica nasceu atrelada, é que estas se assentam, segundo Figueiredo e Santi (2004, p. 54), na ideia de que “[...] o cientista sente-se com o poder e com o direito de lidar com os fenômenos naturais para conhecê-los, desvendar seus mistérios, dominá-los, manipulá-los em experimentos bem controlados, etc.”. Porém, “[...] os procedimentos científicos exigem que os cientistas sejam capazes de objetividade [grifo dos autores], isto é, que deixem de lado seus preconceitos, seus sentimentos e seus desejos para obterem um conhecimento verdadeiro [grifo dos autores (Figueiredo \& Santi, 2004, p. 54)]”.

Estes dois fatores favoreceram embates no campo dos estudos psicológicos e direcionaram preceitos e práticas que configuram a diversidade teórica e metodológica dos vários projetos nascidos no período compreendido entre o final do século XIX e o início do século XX.

Um desses embates diz respeito ao papel da Psicologia científica que:

[...] gerada nos laboratórios de fisiologia experimental, fortemente influenciada pela teoria da evolução natural e pelo exaltado cientificismo da época, tornou-se especialmente apta a desempenhar seu primeiro e principal papel social: descobrir os mais e os menos aptos a trilhar a carreira aberta ao talento supostamente presente na nova crença na chegada de uma vida social fundada na justiça. Entre as ciências que na era do capital participaram do ilusionismo que escondeu as desigualdades sociais, historicamente determinadas, sob o véu de supostas desigualdades pessoais, biologicamente determinadas, a psicologia certamente ocupou posição de destaque (Patto, 1999, p. 58, grifos da autora). 
Em que pese tais direções da Psicologia científica, muitos estudos buscam superar uma visão de ciência psicológica pautada na neutralidade e na objetividade, tendo como norte a historicidade, não sem embates e contradições. Em solo brasileiro a expansão da Psicologia científica ocorreu, em grande medida, com o significativo apoio da Liga Brasileira de Higiene Mental (LBHM) ${ }^{1}$ : entidade civil, criada em 1923, pelo médico Gustavo Riedel (1887-1934) e formada, majoritariamente, por médicos, educadores, juristas, literatos, autodenominados higienistas ${ }^{2}$. Como objetivo básico de propagar ideias sobre higiene mental, os higienistas encontraram nos saberes psicológicos um campo fértil para ampliar seu ideário, tendo como principais focos de atuação a família e a escola e, como um dos principais objetos de intervenção, a criança em idade escolar. Ao afirmar que "a base científica da higiene mental é a psicologia", Fontenelle (1925, p. 02) exprimia os anseios daqueles que entreviam na Psicologia um dos sustentáculos teóricos que forneceriam o embasamento científico para o projeto de nação próspera e desenvolvida que almejavam para o Brasil.

De acordo com Nagle (1976, p. 03), nesse período havia no Brasil "um clima de efervescência ideológica e de grande inquietação social", além de um "alto grau de perturbação provocado pelas campanhas presidenciais", pelo "alastramento das incursões armadas" pelas "lutas reivindicatórias do operariado" e também pelas "pressões da burguesia industrial". Tais impasses revelavam intensos conflitos relacionados aos conglomerados urbanos que então se formavam em função da estrutura fundiária ligada ao uso da mão de obra estrangeira que dispensava tanto o excedente de imigrantes quanto os ex-escravos, em um contexto de incipiente desenvolvimento industrial.

Em função dos ideais de progresso da nação, pouco a pouco, naquele início de século, foram sendo delineados os encaminhamentos sócio-político e educacionais que se refletiriam nas produções da época, bem como sendo gestados os ideais de desenvolvimento nacional. A LBHM participou ativamente de tais direcionamentos, tanto como protagonista, quanto como executora, buscando suas bases teóricas nos conhecimentos científicos disponíveis. Nesse ínterim, embora não tenha sido a única ciência a constituir os alicerces da LBHM, visto que ora disputava espaço ora somava esforços com a Psicanálise, a Psiquiatria e a Eugenia, além da própria Medicina e da Antropologia Física, as quais também intentavam contribuir para a construção de um projeto de modernidade para o Brasil (Costa, 1989; Herschmann, Kropf, \& Nunes, 1996; Reis, 1994), foi da parceria entre a Psicologia e a LBHM que surgiram e se intensificaram as ações de aferição das diferenças individuais, das quais nos ocuparemos neste texto. 


\section{A Valorização da Psicologia sob as Lentes da Higiene Mental}

De acordo com Massimi (2008, 2013), ao estudarmos a história da Psicologia no contexto brasileiro, podemos afirmar que o conhecimento psicológico desenvolvido até o final do século XIX incidiu sobre uma re-elaboração do saber produzido em alguns países europeus e nos Estados Unidos. Esta influência europeia e norte-americana se fez presente em diversas áreas da Psicologia. Estendendo-se até as primeiras décadas do século XX, tal enfoque, com algumas exceções (Bomfim, 1928/1996; Leite, 1976), escamoteou, em suas análises, as condições de vida da população não levando em conta que as desigualdades sociais e de raça/etnia seriam fatores que deveriam ser considerados nas aferições das desigualdades pessoais, conforme frisou Patto (1999).

Tais condições sociais estavam presentes em um cenário de dificuldades econômicas, políticas e sanitárias decorrente das demandas configuradas no final do Império e início da República, com a mudança de modelo econômico e a tentativa de desenvolvimento de um projeto de civilização para o país (Neves, 2003). Neste contexto, o panorama político revelava a existência de condições materiais distintas que começavam a se confrontar: de um lado o esforço para manter a ordem política nacional e, de outro, a busca de sua alteração. Esta variedade de orientações ideológicas tinha como fatores desencadeantes “[...] o processo imigratório, a industrialização incipiente e a urbanização crescente, trazendo novas feições às cidades em meio a um quadro sanitário-educacional precário" (Nagle, 1976, p.11).

Ao tomarmos como referência o período compreendido entre as primeiras décadas do século XX, encontramos abundantes e significativos exemplos sobre a atuação da Psicologia no Brasil nas mais diversas áreas (educação da mulher e da criança, saúde, exército etc.), tanto como extensão ou reprodução de estudos estrangeiros ou mesmo como produções nacionais, fortemente influenciadas por estudos pioneiros trazidos de outros países (Caldas, 1929; Roxo, 1925; Radecki, 1925; Piéron, 1931).

Nesta perspectiva, uma das maneiras de realizar, compreender e veicular estudos sobre temas voltados à Psicologia e sobre as formas de intervenção desta ciência pode ser verificada nos Archivos Brasileiros de Hygiene Mental (ABHM), periódico criado em 1925 e editado até 1947 com a finalidade de divulgar os trabalhos da LBHM. Os Archivos, enquanto órgão oficial de propaganda da LBHM “[...] têm uma grande e nobre missão a realizar: órgão de doutrina e combate, eles se propõem a abrir, em nosso meio, a senda por onde possam enveredar, crescer e frutificar os ideais de higiene mental e eugenia, que consubstanciam o programa daquela Instituição" (Caldas, 1929, p. 01). Pretendia-se que este periódico fosse 
“[...] não só um repositório do que se publique sobre o assunto em nosso meio, ou alhures, mas também, se possível, um núcleo e atração de prosélitos, no amplo domínio dessa Higiene Mental, que com justo direito aspira tornar-se 'moral universal de amanhã'" (Fontenelle, 1925, grifo do autor).

Nos Estatutos da LBHM constavam os objetivos e formas de aplicação dos meios para alcançar os objetivos voltados à higiene mental os quais se referiam fundamentalmente à divulgação dos seus preceitos por meio da propagação das ideias sobre higiene mental, realização de eventos, publicações, além da instalação de uma biblioteca aberta ao público interessado no tema. Nesta empreitada, em inúmeras edições dos Archivos há publicações consoantes à Psicologia com vistas a fomentar a higiene mental ${ }^{3}$. Isto pode ser visto em um editorial que tem como título Phychologia e Hygiene Mental, onde esta correlação é enfatizada:

[...] se existem métodos de realizar higiene mental, que em nosso meio necessitem de estímulo e de incentivos para o seu aperfeiçoamento, não são eles por certo, os métodos psiquiátricos, que os numerosos e proficientes especialistas nacionais poderão aplicar em qualquer momento, tendo recursos materiais para o fazer - senão os métodos psicológicos propriamente ditos[grifo nosso], e destes, sobretudo, os psico-experimentais, quantitativos e qualitativos[...] (Editorial, 1930, p. 311).

Nesse propósito, à Psicologia eram atribuídas várias tarefas com as quais se visava:

[...] a justa avaliação das mentalidades normais, trabalho prévio imprescindível a uma série de aplicações especifica da higiene mental, em sentido estrito, quer dizer concernente aos indivíduos sãos de espírito: orientação profissional, seleção psicológica dos escolares, saúde mental dos operários, etc. (Editorial, 1930, p. 311)

Mas, o que seria higiene mental? Por que tanta importância era dada a este conceito? Pelo seu valor enquanto uma das principais razões para a criação da LBHM, o conceito de higiene mental necessita especial destaque já que inclui diversas demarcações, conforme os ideais que sobre ele incidiram por parte de diversas categorias profissionais nele envolvidas, tendo como requisito básico alcançar o objetivo precípuo traçado nas primeiras décadas do século XX: tornar o Brasil uma nação próspera, moderna e alinhada aos países que eram modelos a serem seguidos, eminentemente os Estados Unidos e alguns países da Europa 
como França, Inglaterra e Alemanha. Nesse caso, o conceito de higiene mental incluía diversas nuanças que, grosso modo, envolviam ações voltadas à busca de um ideal de homem pautado em preceitos sobre condutas e procedimentos que, segundo os higienistas, levariam a um nível de desenvolvimento estabelecidos como meta. Sobre tal intento, Fontenelle (1925, p. 09) advoga que medidas que incluíssem um esforço coletivo trariam resultados muito vultosos, visto que "[...] se multiplicariam as fontes de propaganda dos grandes princípios que põem na educação os fundamentos da higiene mental, cultivando e preparando as mentalidades individuais para o correto ajustamento futuro, base da saúde, do trabalho e da felicidade".

Nesta perspectiva, como a LBHM agregava profissionais de diferentes áreas (formados em Medicina, Direito, interessados em Psicologia, Educação, atuantes em política, em jornais), havia entre eles posicionamentos teóricos tanto convergentes, quanto divergentes. Isto produzir diferenças nas definições de higiene mental apresentadas nos Archivos e em outras formas de disseminação de seus preceitos ${ }^{4}$.

Uma destas definições foi proposta pelo psicólogo polonês Waclaw Radecki (18871953) que definia higiene mental como “[...] uma ação que forma as condições da vida, capazes de assegurar o desenvolvimento normal[grifo do autor] em todos os domínios da vida psíquica da criança" (Radecki, 1925, p. 20-21). Consoante a esse pensamento, o médico sergipano Manoel Bomfim (1868-1932) em sua obra "Lições de Pedagogia", originalmente publicada em 1915, também propunha ações de higiene mental visando "o apuro do caráter e a organização do proceder", tendo como objetivo "[...] opor tendências, ou instintos, uns aos outros, desenvolver e reforçar os bons pelo exercício; deixar atrofiar os maus, evitando as tentações, organizar os hábitos, de sorte que sobre eles tenha sempre a vontade um poder eficaz" (Bomfim, 1926, p. 387).

O médico e professor Henrique Roxo (1877-1969) enfatizava o papel da educação escolar como veículo de promoção da higiene mental, recomendando a intervenção educacional adequada, visando assegurar a saúde mental da criança, visto que “[...] os maus processos pedagógicos podem influenciar na gênesis de degeneração mental, assim também a boa orientação impressa à educação de uma criança pode salvaguardá-la do desequilíbrio psíquico" (Roxo, 1925, p. 06). Fundar critérios de normalidade para o desenvolvimento infantil e, mesmo para recuperar as condutas consideradas desviantes no adulto, bem como estabelecer padrões para alcançá-los, eram uma tônica constante nos projetos da LBHM. Tal discurso, fortemente apreendido por profissionais da medicina e da educação, produziram ressonâncias nos mais variados aspectos da vida cotidiana, nas diferentes práticas sociais. 
Enquanto diretor do Laboratório de Psicologia na Colônia dos Alienados no Engenho de Dentro, Radecki (1925, p. 12) recorria aos preceitos da Psicologia científica sobre o desenvolvimento infantil para defender que “[...] a criança não é um homem adulto em miniatura, mas representa período qualitativamente diferente, onde as leis fundamentais da Psicologia geral, não perdendo o seu valor, referem-se, entretanto, a outras funções que não as que no homem adulto se encontram". Também tendo como mote o desenvolvimento infantil, o presidente da LBHM, o médico Ernani Lopes (1885-?), expressava seu posicionamento em favor da necessidade de se detectar precocemente transtornos mentais na criança de modo a realizar intervenções já nos primeiros anos de vida. Segundo ele:

$\mathrm{Na}$ era clínica contemporânea, caracterizada sobretudo pela preocupação do diagnóstico precoce, já não satisfaz aos especialistas o mero estudo das psicoses da infância. Começa-se enfim a compreender o alto interesse de surpreender, já na infância, certas psicoses do adulto, rastreáveis com grande antecedência pelas suas leves manifestações prodrômicas ou incipientes (Lopes, 1930a, p. 246, grifos do autor). Para a imensa maioria destes estudiosos, a infância era o período mais propício e a Psicologia o conhecimento que forneceria os meios para a detecção e prevenção de desajustes, podendo permitir“[...] o perfeito ajustamento do organismo às condições do meio, por intermédio de impulsos que levam à ação conveniente, seja reflexa ou inconsciente, seja voluntária ou escolhida" (Fontenelle, 1925, p. 02).

Sobre a intervenção da ciência psicológica em diversos setores da sociedade, nos Archivos podem ser resgatados diversos exemplos desta inserção na vida cotidiana da população. Um deles é de Lopes (1930b) que, citando um estudo desenvolvido em Genebra, ao tratar da "psicologia do operário", destaca que seria preciso que estes trabalhadores encontrassem satisfação no trabalho. Ele ainda adverte sobre reações psicopatológicas ligadas ao ritmo e à duração da jornada de trabalho.

No campo educacional, Braga (1931, p. 04), ao se referir a pesquisas das áreas da Psicologia e Pedagogia desenvolvidas no Brasil com o uso de testes psicométricos, diz que a primeira daria "[...] à educação um magnífico aparelhamento para aferir a capacidade mental [para] verificar o rendimento dos processos didáticos e avaliar os resultados obtidos”. Nesta perspectiva, em um contexto de efervescência pela construção de um novo projeto de sociedade, no Brasil os saberes psicológicos emergentes se fizeram presentes cada vez mais ao longo das primeiras décadas do século XX, no intuito de construir "[...] uma nova nação, 
[o qual] demandava a formação de um homem novo, apto para as exigências de um novo modelo produtivo e de novas relações de trabalho, tarefa essa que deveria ser empreendida pela educação" (Antunes, 2003, p. 151, grifos da autora).

\section{Educação e Psicologia: Promessas de Redenção no Limiar da República}

Mesmo tomando os devidos cuidados de não considerar que a Psicologia científica brasileira tenha afiançado visões naturalizantes e fortalecido concepções que avalizassem uma suposta igualdade natural entre os homens, é importante frisar que esta ciência, instituída no final do século XIX e regulamenta enquanto profissão no país na segunda metade do século $\mathrm{XX}$, em muitos aspectos não esteve totalmente alinhada a bandeiras comprometidas ou voltadas aos direitos daqueles que são cotidianamente oprimidos e excluídos em função de sua raça/etnia, identidade de gênero, origem social ou condição econômica. Fazendo um recorte sobre a atuação da Psicologia em sua relação com a Educação pública e, mais especificamente, sobre a inserção do seu saber/fazer nas questões que perpassam o cotidiano escolar, definindo fatores que vicejam no contexto educacional, é possível identificar fatores que historicamente foram negligenciados quando se trata de elucidar as causas do fracasso escolar ou os verdadeiros determinantes dos altos índices de evasão e repetência que atravessaram todo o século XX e que, no limite, permanecem inquietantes até o momento atual.

Mas, por que estamos fazendo tais conjecturas? Porque a história da Psicologia no Brasil, desde que contada de forma crítica e contextualizada, pode desvelar que seu percurso enquanto ciência chamada a resolver os impasses ocorridos na escola foi sempre na direção de estabelecer critérios de aferição de uma suposta normalidade e de realizar a seleção dos capazes e dos incapazes, tanto para fatores relacionados a padrões de conduta e de comportamento, quanto para fatores relacionados a aprendizagem de conteúdos acadêmicos. Neste processo, tanto a Pedagogia como a Psicologia, segundo Patto (1999, p. 62), dedicaramse a "[...] identificar e promover socialmente os mais aptos, independentemente de sua etnia ou de sua origem social". Nesse processo de aferição das diferenças sob a égide dos "talentos e aptidões naturais" foi desconsiderado um fator fundamental: "[...] as possibilidades reais de ascensão, numa sociedade democrática, são, por definição, desiguais [grifo da autora]" (Patto, 1999, p. 62).

Importante considerar que o acesso à Educação nesse período - início do século XX era basicamente restrito às camadas abastadas, ou seja, estava voltado a uma pequena elite, 
favorecida por questões étnicas, sociais e econômicas. Com o atraso educacional que atingia a imensa maioria da população, quase toda analfabeta, havia por parte de muitos intelectuais o ideal educacional de expandir o ensino às camadas populares com vistas a alcançar o bemestar coletivo e o desenvolvimento moral, como meios de se alcançar a produção de riquezas para o país (Bomfim, 1926). Reportando-se a isso, Penna (1927/1997) afirma que:

A imensa maioria da população brasileira desconhece rudimentos de biologia e de higiene; vegeta, por isso, em apavorante estado patológico e de miséria, sem capacidade para exercer a finalidade biopsíquica do homem, de defesa e melhoramento incessante da vida individual, da família, da sociedade e da espécie, limitando-se a realizar, em péssimas condições, a finalidade bioinstintiva dos irracionais, reduzida à conservação do indivíduo, pela nutrição, e à perpetuação da espécie, pela reprodução. Ao contrário, o seu concurso de indolentes, de depositários e propagadores de doenças e de taras patológicas é de contínua e progressiva degeneração da raça e da espécie. Dessa incapacidade biopsíquica do povo brasileiro resulta o trabalho escravizado e improdutivo, a miséria econômica, a falência financeira, a do caráter das elites e uma mentalidade coletiva caótica, inconsciente, passiva, sem aspirações, sem rumo e sem aptidão para criar a consciência nacional. (Penna, 1927/1997, p. 33)

Ou seja, ocorria uma inversão de causa-e-efeito. A incapacidade do povo levava às péssimas condições de trabalho, ao perverso caráter da elite, a uma mentalidade passiva. Neste contexto sócio-histórico que se desenrolava nas primeiras décadas do século XX, fortemente marcado pela mudança de modelo econômico, de agrário-exportador para urbanoindustrial, paulatinamente começava a "preparação do terreno" para a difusão do ideário da Escola Nova no Brasil, passando a ocorrer, de um lado, uma "[...] modesta infiltração destes ou daqueles procedimentos, ideias ou práticas" diferentes das cultuadas na Escola Tradicional e, de outro, determinadas "[...] condições facilitadoras para a mais sistemática e ampla difusão posterior do ideário" (Nagle, 1976, p. 239).

Particularidades que se delineavam no período transcorrido entre o fim do Império e as primeiras décadas da República, tais como a imigração e o fim da escravidão, demandavam a necessidade de investimentos em preparação de mão-de-obra qualificada e plenamente educada para atender uma nova organização do trabalho. Nesse sentido, a partir dessas novas contingências, parecia ser necessário o empreendimento de esforços conjuntos de várias 
ordens para suprir os anseios de formação de uma nacionalidade, a qual não fora garantida nas atuações imperiais do século XIX.

Um entrave a esta pretensão era a integração do imigrante europeu, de fundamental importância, visando garantir a ordem necessária à consolidação do novo regime político, nascido no final do século anterior. Nesse sentido, esse elemento novo na população brasileira representava inúmeros impasses sociais quanto aos costumes, à língua e, principalmente, quanto à forma de estabelecer relações de trabalho. Aliado a esses percalços, havia a herança da escravidão representada pelos ex-escravos cujo novo lugar social mantinha a marca do legado da servidão nos, desde então, considerados cidadãos. Este espólio foi amplamente analisado por diversos estudiosos da área (Fernandes, 1978; Ianni, 1962; Schwarcz, 1993).

Um esforço conjunto considerado fundamental para superar tais obstáculos foi a gestação de um sentimento nacionalista que pudesse agregar e unificar valores e crenças em prol do progresso de todos. Na obra A Educação Nacional, publicada em 1910, Veríssimo (1985) defende que a busca do nacionalismo, via Educação, seria um importante fator de desenvolvimento:

A educação nacional, largamente derramada e difundida com o superior espírito de ser um fator moral de nacionalismo, poderosissimamente concorreu para despertar no americano o sentimento patriótico. Teve esse grande povo a intuição de que a escola, isto é, a mesma educação prodigamente distribuída a todos os cidadãos, devia ser a cadeia que ligasse os elementos heterogêneos da nação. (Veríssimo, 1985, p. 45, grifo nosso)

Analisando as questões educacionais presentes no contexto histórico das sociedades humanas, Nagel (1992, p. 1) mostra que o conteúdo dos discursos feitos em prol da mudança no modelo educacional pode ser considerado a expressão direta de novas exigências da sociedade. Portanto, “[...] quando novos padrões de acumulação emergem ou quando um determinado tipo de acumulação não está se viabilizando, a comoção social se instaura e, nesse período de abalo generalizado, a educação é convocada para prestar contas à sociedade do que não fez!" (Nagel, 1992, p. 1, grifo nosso).

Dessa forma, a partir do início do século XX, no Brasil, a Educação passou a ser considerada o caminho certeiro para debelar a "falta de gosto pelo prático", a "falta de amor ao trabalho", a "falta de amor às grandes realizações", a "[...] falta de profissões independentes da burocracia, capazes de engrandecimento da pátria" (Nagel, 1992, p. 5). 
Nessa direção, a incapacidade para adaptação às novas exigências do mercado, ou seja, às condições de mão de obra operária treinada para tarefas a serem executadas nas linhas de produção em série e pautadas em regras específicas para a produção, porém carente de legislação que trouxesse garantia de direitos em termos de salários e de condições de trabalho, eram consideradas consequência dos altos índices de analfabetismo.

Em vista da finalidade de superação de tais condições, o movimento da Escola Nova, nascido no final do século XIX, na Europa, como expressão de uma necessidade histórica "de preparar para o mundo do trabalho e formar o cidadão" (Leonel, 1998, p. 94), foi instituído no Brasil, segundo Lopes (1984, p. 24), com a missão de debelar o grande desafio de "levar adiante um novo modo de produção" e "ampliar as oportunidades educacionais", pois "era necessário uma escola nova”. Isto seria alcançado com a contribuição da Biologia e da Psicologia que seriam o suporte para o conhecimento da criança, seus estágios de maturação e suas diferenças individuais.

Em solo brasileiro, um dos pioneiros do movimento escolanovista foi o educador Manuel Bergström Lourenço Filho (1897-1970). Em sua obra Introdução ao estudo da Escola Nova, publicada em 1930, Lourenço Filho lança bases educacionais assentadas em conhecimentos originários da biologia, da psicologia e da sociologia. Os princípios gerais da Escola Nova - os conceitos de atividade, interesse e motivação - são destacados com o fim de promoverem novas práticas educacionais (Lourenço Filho, 1930). Nessa empreitada em favor do desenvolvimento da nação brasileira, a criança passa a ser estudada cientificamente: sobre ela “[...] convergem-se estudos, testes, medidas, programas, métodos e metodologias” (Lopes, 1984, p. 25).

Neste contexto de mudanças em relação aos preceitos educacionais, membros da LBHM envidavam esforços para contribuir com os novos ideais pedagógicos somando-se à “[...] Cruzada Pedagógica pela Escola Nova” (Leme Lopes \& Fialho, 1929, p. 68). Tal contribuição ocorreria principalmente pelo emprego dos testes psicológicos visando o balizamento intelectual, "a formação de classes homogêneas do ponto de vista intelectual" visto que “[...] não é possível ministrar os mesmos conhecimentos, submeter ao mesmo plano de estudo, alunos de capacidade mental diversa [grifo nosso]”. (Leme Lopes \& Fialho, 1929, p. 68)

A relevância atribuída à medida educacional e, por consequência, aos instrumentos de medida psicológica tornou-se um dos pilares de sustentação do movimento escolanovista "[...] dada a importância que nele se atribui ao conhecimento das características do educando, tais como as suas formas de percepção, inteligência, interesses, capacidades, destrezas" (Nagle, 
1976, p. 248). Analisando tal conjuntura, Bock (2003, p. 82) avalia que a entrada da Psicologia na Educação ocorreu porque no modelo instituído pela Escola Nova seria preciso "[...] conhecer a criança e seu desenvolvimento natural, sem ser corrompido, para poder trabalhar para mantê-la assim". Nesse caso, "[...] era preciso saber como se dá o desenvolvimento natural das crianças para poder vigiá-las deste ponto de vista". Tais preceitos estavam contidos nos ideais lançados no Manifesto dos Pioneiros da Educação Nova (2006, p. 191) segundo o qual a educação deveria assumir "a sua verdadeira função social" de "[...] dirigir o desenvolvimento natural e integral do ser humano em cada uma das etapas de seu crescimento, de acordo com uma certa concepção do mundo".

Ao longo das décadas seguintes a Psicologia ganhou cada vez mais importância no cenário educacional sendo amplamente difundida nas Escolas Normais, as quais, segundo Antunes (2003, p, 156) foram "o grande sustentáculo para o desenvolvimento da Psicologia Educacional no Brasil", visto que, nestes espaços, foi impulsionada a “[...] produção de pesquisas e a formação de profissionais que viriam a fazer parte do grupo de pioneiros da Psicologia”. Conforme Antunes (2003), diversos pioneiros da Psicologia brasileira, que não se cansaram de empreender esforços para construir e divulgar saberes psicológicos rumo à sua autonomização enquanto profissão no início do século $\mathrm{XX}$, estavam entre os membros da LBHM, tais como: Manoel Bomfim, Maria Brasília Leme Lopes (1909-1996), Lourenço Filho, Isaías Alves (1888-1968).

No bojo deste projeto, as demandas da Educação para a Psicologia se faziam por meio da busca de uma medida de normalidade ou da detecção de incapacidades e disfuncionalidades que seriam entraves à formação de futuros trabalhadores manuais ou intelectuais. Nesse ínterim haveria "[...] a necessidade urgente de fixar uma escala de nível mental para a seleção dos alunos das diversas classes" (Leme Lopes \& Fialho, 1929, p. 70), de modo a fixar uma medida intelectual que fosse capaz de estabelecer critérios com os quais pudessem ser definidas as funções de cada indivíduo na sociedade[grifo nosso] visando seu melhor aproveitamento. Para tanto, Roxo $(1925$, p. 6) propunha a elaboração de uma "ficha médico-psicológica" que consistiria “[...] não só na discriminação dos estudantes em classes adequadas à sua capacidade intelectual, como também no melhor aproveitamento em outros ramos de atividade humana daqueles que não dão para o estudo [grifo nosso]".

Reafirmando a importância atribuída à Psicologia e, mais especificamente, aos testes psicométricos, um dos Editoriais dos Archivos destaca que: 
A esse propósito nunca será bastante insistir sobre o enorme progresso que representa a moderna corrente de psicologia dos testes mentais, usados e representados com o rigorismo necessário, para o que muito concorre o precioso auxílio dos processos matemáticos, em sua pluralidade transportados do campo da estatística para o das aplicações psicológicas (Editorial 1930, p. 312).

Neste contexto, embora os saberes da Psicologia e Pedagogia pudessem influenciar-se mutuamente, não é tarefa simples balizar suas legítimas convergências e divergências em muitos aspectos, visto que havia entre eles diferentes formas de inserção e diferentes atores sociais enquanto agentes de produção e difusão de tais concepções e práticas.

\section{O que Temos Hoje? Em que Podemos Avançar?}

Passadas várias décadas desde a instituição de uma concepção de busca de um ideal de homem e de nação, do qual a Psicologia participou intensamente e ofereceu inúmeras contribuições no sentido de respaldar saberes e fazeres voltados ao objetivo estabelecido nas primeiras décadas da República, algumas considerações podem ser feitas. Ao visitarmos o site do Conselho Federal de Psicologia podemos identificar sua participação em muitas bandeiras de luta em prol da garantia de direitos, em geral destinados às denominadas minorias, tais como: mulheres vítimas de violência, população LGBT, adolescentes em conflito com a lei, pessoas em situação de rua, imigrantes, pessoas com deficiência, entre outras camadas da população. É possível encontrar também bandeiras mais abrangentes que não se inserem em grupos específicos, como é o caso da defesa dos direitos à saúde e educação de qualidade. Tais bandeiras denotam o compromisso com perspectivas voltadas aos direitos humanos e, mais especificamente, aos direitos daqueles que são oprimidos pela sua condição de vulnerabilidade social e/ou econômica em uma sociedade assentada na desigualdade de classes. Em que pese diferentes ponderações, temos claro que a Psicologia defende estas bandeiras. Nesse ínterim, após mais de um século de institucionalização, em diversos momentosa Psicologia revisitou seus princípios e re(conheceu) suas bases, visando atuar em favor de um compromisso com os segmentos sociais historicamente excluídos. Este compromisso visa suplantar a visão idealizada de homem e de mundo que constituiu seus alicerces científicos no século XIX.

Nesse compasso, muitos profissionais estão, com certa frequência, questionando suas práticas e buscando compreender em que os saberes psicológicos podem contribuir para 
ampliar avanços e evitar retrocessos em relação aos conhecimentos científicos produzidos nas últimas décadas. Desse processo de repensar surgem questões: o que temos hoje? Em que podemos avançar, por exemplo, acerca da superação da prática da aferição das diferenças individuais, seja no contexto educacional ou em outras áreas da vida em sociedade? O que tais práticas representam em termos de demérito ou desqualificação dos denominados incapazes, desviantes, insurgentes...?

No caso da parceria cunhada entre a LBHM e a Psicologia, esta ainda em fase de autonomização no início do século XX, em prol de um projeto de nação para o Brasil em um momento de mudanças conjunturais nas relações de produção, é possível aventar que tal parceria foi bem sucedida, visto que tanto a LBHM deu visibilidade aos saberes psicológicos em solo brasileiro, quanto estes robusteceram o ideário da higiene mental, servindo de base científica aos projetos voltados a estabelecer padrões ou medidas de normalidade, principalmente no contexto da educação escolar. As ressonâncias de tal intuito ainda reverberam enquanto práticas de muitos psicólogos que atuam no contexto escolar/educacional e se dedicam a demarcar as diferenças individuais pela ótica da aferição do Quociente Intelectual.

Tal labor, levado quase que à exaustão na primeira metade do século XX, legitimado em nome de um saber que propunha se firmar como neutro e a explicar e debelar as causas da não aprendizagem e do fracasso escolar, levou a Psicologia a refletir sobre seus métodos e técnicas e também sobre seu projeto enquanto ciência, no intuito de repensar a quem serve quando busca enquadrar, balizar, aferir ou estabelecer um padrão de normalidade, seja no âmbito cognitivo, seja no afetivo ou psicossocial. Tais reflexões novamente trouxeram desdobramentos nas mais variadas áreas de inserção dos saberes psicológicos. E, com especial ênfase, nos processos de classificação do desenvolvimento humano com a utilização dos "testes mentais".

Um exemplo bastante marcante e que está intimamente ligado à atuação do psicólogo no contexto escolar/educacional é a delimitação das diferenças individuais com a aferição das capacidades intelectuais. Estamos nos referindo à avaliação psicométrica ou, mais precisamente, ao uso de testes de inteligência ou de classificação do Quociente Intelectual (QI) para avaliar dificuldades do processo de escolarização. A despeito de severas e contundentes críticas tecidas por renomados psicólogos da área escolar/educacional (Moysés \& Collares, 1997; Patto, 1997, 1999; Proença, 2004), ainda é recomendada e aferição da inteligência, via testes psicométricos (Conselho Federal de Psicologia, 2013) os quais se 
assentam na perspectiva de que as capacidades cognitivas sejam uma função inata, estática ou, quando muito, desenvolvida à parte de todo e qualquer contexto sócio histórico e cultural.

Agravante maior é que a imensa maioria dos profissionais ainda são seduzidos pela suposta legitimidade que esta tarefa de aferidor lhes confere. Tal afirmação pode ser verificada nos laudos de avaliação pautados nos testes psicométricos (Alves, Rosa, Silva, \& Sardinha, 2016). Nesse caso, entendemos que a Psicologia, grosso modo, ainda não superou a condição de algoz da criança que expressa dificuldades no processo de escolarização, visto que, assim como afirma Proença (2004, p. 35), explicar o desenvolvimento humano e, mais especificamente, o desempenho escolar conforme resultados de instrumentos de medida psicológica, pode ser uma tarefa que "[...] nega as influências e/ou determinações das relações institucionais e sociais sobre o psiquismo, encobrindo as arbitrariedades, os estereótipos e preconceitos de que as crianças das classes populares são vítimas no processo educacional e social".

Desse modo, buscar respostas para os impasses que perpassam a atuação da Psicologia enquanto ciência que se ocupa das questões humanas em suas expressões individuais e coletivas, não é fácil, nem simples. Há reflexões a serem continuamente feitas e refeitas. Há questões a serem debatidas e, quiçá, revisitadas e revistas. Porém, o momento histórico atual inspira ponderações sobre quais espaços temos para fazer revisões críticas e quais espaços são tomados com pautas conservadoras. O cotidiano mostra que, apesar das conquistas engendradas, principalmente, nos últimos 30 anos, com a criação de legislação sobre acesso a direitos, o pêndulo se volta mais para a segunda posição.

Quase todos os dias assistimos estarrecidos notícias veiculadas pelos meios de comunicação de massa que denunciam um viés totalitário e conservador na condução das políticas públicas que depõem contra os princípios de um regime democrático. Tal visão abarca discursos e práticas, tanto no Brasil como no mundo com um todo, tais como: repúdio a imigrantes e refugiados, desprezo pela democracia e pela liberdade de expressão e formas de viver que não sejam enquadradas como normais, política de austeridade que impõe sacrifícios à sociedade para além do que é possível suportar, banalização da violência contra grupos desvalidos socialmente, como sem tetos e moradores de comunidades pobres, entre outros.

Um exemplo de desprezo pela democracia na condução das políticas públicas é a Reforma do Ensino Médio no Brasil que, ao suprimir dos currículos a obrigatoriedade das disciplinas de Filosofia e Sociologia, ventila a intenção de minimizar ou, no mínimo, desestimular o debate em torno de questões que propõem reflexões sobre a relação educação e 
sociedade de classes. No rastro desse movimento de desmonte do pensamento crítico está o Projeto Escola Sem Partido ${ }^{5}$, visto que, no discurso de seus defensores, a argumentação soa como valorização da pluralidade de opiniões, porém, na prática, é uma tentativa deliberada de impor a censura e culpabilizar o professor, contrariando a Constituição Federal (Brasil, 1988) que prevê o "pluralismo de ideias e concepções pedagógicas" no contexto escolar. Enfatizando tal análise, Barzotto (como citado em Matuoka, 2018) afirma que "[...] a dimensão política não pode ser retirada dos eventos humanos, portanto, nem da educação. A tendência, de fato, é silenciar toda e qualquer visão mais à esquerda ou de promoção da igualdade e respeito à diversidade".

Tais riscos de retrocessos nos levam a pensar que vivemos em tempos difíceis. E a Psicologia enquanto ciência e profissão necessita posicionar-se sobre esse contexto. Em sua obra Homens em tempos sombrios (2008), Hannah Arendt (1906-1975) relata a história de vários homens e mulheres (Rosa Luxemburgo, Bertold Brecht, Walter Benjamim, entre outros) que viveram em tempos sombrios e que, nem por isso, perderam sua dignidade e humanidade. Isso pode sinalizar que também vivemos em tempos onde, cotidianamente, as formas de resistência necessitam nos visitar.

Sobre uma suposta aferição da normalidade que abona muitas formas de intervenção da Psicologia há mais de um século, entendemos e recomendamos que esta prática seja continuamente objeto de análise e reflexões por parte daqueles que se ocupam em compreender de onde viemos, o que temos hoje e em que podemos avançar. Enfim, frente a tudo que nos força a aceitar o que vem sendo imposto enquanto pautas antidemocráticas, o suspiro que nos move rumo a resistir pode ser a capacidade que a ciência psicológica nos proporciona: a competência para a reflexão. Esta irrompe na possibilidade de suplantara histórica busca de um padrão de normalidade da qual a Psicologia participou e, por vezes, ainda participa e que, por si só, vilipendia as possíveis formas de existir de cada ser humano.

\section{Referências}

Alves, I. C. B., Rosa, H. R., Silva, M. A., \& Sardinha, L. S. (2016). Avaliação da inteligência: Revisão de literatura de 2005 a 2014. Avaliação Psicológica, 15(n. esp), 89-97. doi:10.15689/ap.2016.15ee.09

Antunes, M. A. M. (2003). Psicologia e educação no Brasil: Um olhar crítico. In M. E. M. Meira, \& M. A. M. Antunes (Orgs.), Psicologia escolar: Teorias críticas (pp. 139168). São Paulo: Casa do Psicólogo. 
Arendt, H. (2008). Homens em tempos sombrios. São Paulo: Companhia de Bolso.

Bock, A. M. B. (2003). Psicologia da educação: Cumplicidade ideológica. In M. E. M. Meira, \& M. A. M. Antunes (Orgs.), Psicologia escolar: Teorias críticas (pp. 79-103). São Paulo: Casa do Psicólogo.

Bomfim, M. (1926). Lições de Pedagogia: Theoria e prática da educação (3a ed.). São Paulo: Livraria Francisco Alves.

Bomfim, M. (1996). O Brasil Nação: Realidade da Soberania Brasileira (2a ed.). Rio de Janeiro: Topbooks. (Obra original publicada em 1928).

Braga, E. (1931). Os elementos psycho-sociologicos nos programas de ensino. Archivos Brasileiros de Hygiene Mental, 4(1), 03-16. Recuperado de http://old.ppi.uem.br/gephe/index.php/arquivos-digitalizados/14-sample-dataarticles/85-arquivos-brasileiros-de-higiene-mental

Caldas, M. (1929). Os Archivos Brasileiros de Hygiene Mental. Archivos Brasileiros de Hygiene Mental, 2(1), 01-02. Recuperado de http://old.ppi.uem.br/gephe/index.php/arquivos-digitalizados/14-sample-dataarticles/85-arquivos-brasileiros-de-higiene-mental

Cambaúva, L. G., Silva, L. C., \& Silva, W. (1998). Reflexões sobre o estudo da História da Psicologia. Estudos de Psicologia, 3(2), 207-227. doi:10.1590/S1413294X1998000200003

Conselho Federal de Psicologia. (2013). Cartilha Avaliação Psicológica. Brasília, DF: Autor. Recuperado de http://satepsi.cfp.org.br/docs/cartilha.pdf

Costa, J. F. (1989). História da psiquiatria no Brasil: Um corte ideológico (4a ed.). Rio de Janeiro: Xenon.

Costa, J. F. (2004). Ordem médica e norma familiar (5a ed.). Rio de Janeiro: Edições Graal.

Editorial. (1930). Psychologia e Hygiene Mental. Archivos Brasileiros de Hygiene Mental, 3(9), 311-312. Recuperado de http://old.ppi.uem.br/gephe/index.php/arquivosdigitalizados/14-sample-data-articles/85-arquivos-brasileiros-de-higiene-mental

Fernandes, F. (1978). A integração do negro na sociedade de classes (3a ed.). São Paulo: Ática.

Figueiredo, L. C. M., \& Santi, P. L. R. (2004). Psicologia uma (nova) introdução (2a ed.). São Paulo: Educ.

Fontenelle, J. P. (1925). Hygiene mental e educação. Archivos Brasileiros de Hygiene Mental, l(1), 1-10. Recuperado de http://old.ppi.uem.br/gephe/index.php/arquivosdigitalizados/14-sample-data-articles/85-arquivos-brasileiros-de-higiene-mental 
Gould, S. J. (2014). A falsa medida do homem (3a ed.). São Paulo: Martins Fontes.

Herschamann, M., Kropf, S., \& Nunes, C. (1996). Missionários do progresso: Médicos, engenheiros e educadores no Rio de Janeiro, 1870-1937. Rio de Janeiro: Diadorim.

Ianni, O. (1962). As metamorfoses do escravo. São Paulo: Difusão Europeia do Livro.

Leite, D. M. (1976). O caráter nacional brasileiro: História de uma ideologia (3a ed.). São Paulo: Pioneira.

Leme Lopes, M. B. L.; \& Fialho, I. de A. (1929). Suggestões para o emprego dos tests. Trabalhos originaes. Archivos Brasileiros de Hygiene Mental, 2(2), 68-77. Recuperado de http://old.ppi.uem.br/gephe/index.php/arquivos-digitalizados/14-sample-dataarticles/85-arquivos-brasileiros-de-higiene-mental

Leonel, Z. (1998). Para ler os clássicos: Lições de Montaigne. Intermeio: Revista do Mestrado em Educação, 4(8), 87-97. Recuperado de https://periodicos.ufms.br/index.php/intm/article/view/2650

Lopes. E. (1925). Trabalhos da Liga de Hygiene Mental. Archivos Brasileiros de Hygiene Mental, 1(1), 151-164. Recuperado de http://old.ppi.uem.br/gephe/index.php/arquivosdigitalizados/14-sample-data-articles/85-arquivos-brasileiros-de-higiene-mental

Lopes, E. (1930a). Menores incorrigíveis. Archivos Brasileiros de Hygiene Mental, 3(7), 241246. Recuperado de http://old.ppi.uem.br/gephe/index.php/arquivos-digitalizados/14sample-data-articles/85-arquivos-brasileiros-de-higiene-mental

Lopes, E. (1930b). A hygiene mental do operário. Resenhas e Analyses. Archivos Brasileiros de Hygiene Mental, 3(7), 257-258. Recuperado de http://old.ppi.uem.br/gephe/index.php/arquivos-digitalizados/14-sample-dataarticles/85-arquivos-brasileiros-de-higiene-mental

Lopes, E. M. T. (1984). O escolanovismo: Revisão crítica. In G. N. Mello (Org.), Escola nova, tecnicismo e educação compensatória (pp. 19-28). São Paulo: Loyola.

Lourenço Filho, M. B. (1930). Introducção ao estudo da Escola Nova. São Paulo: Cia. Melhoramentos.

Manifesto dos Pioneiros da Educação Nova (1932). (2006). Revista HISTEDBR On-line, (n.esp.), 188-204. Recuperado de http://www.histedbr.fe.unicamp.br/revista/edicoes/22e/doc1_22e.pdf

Marx, K., \& Engels, F. (1968). Carta a W. Borgius em Bratislava (Heinz Starkenburg), 25 de janeiro de 1894 [Engels, F. Brief an Walther Borgius in Breslau - Heinz Starkenburg]. In E. A. München (Trad.), Obras de Karl Marx e Friedrich Engels (Vol. 39, pp. 205), 
Berlim: Dietz. Recuperado de http://www.scientificsocialism.de/FundamentosCartasMarxEngelsCapa.htm

Massimi, M. (2008). Estudos históricos acerca da psicologia brasileira. In R. H. Freitas (Org.), História da psicologia: Pesquisa, formação, ensino (pp. 69-83). Rio de Janeiro: Centro Edelstein de Pesquisas Sociais.

Massimi, M. (2013). O processo de institucionalização do saber psicológico no Brasil do século XIX. In A. M. Jacó-Vilela, A. A. L. Ferreira, \& F. T. Portugal (Orgs.), História da Psicologia: Rumos e percursos (3a ed. rev. e ampl., pp. 181-192). Rio de Janeiro: Nau.

Matuoka, I. (2018, Maio 24). Por que o Escola Sem Partido vai contra o papel da escola?. Centro de Referências e Educação Integral. Recuperado de https://educacaointegral.org.br/reportagens/por-que-o-escola-sem-partido-vai-contrao-papel-da-escola/

Moysés, M. A. A., \& Collares, C. A. L. (1997). Inteligência abstraída, crianças silenciadas: As avaliações de inteligência. Psicologia USP, doi:10.1590/psicousp.v8i1.107579

Nagel, L. H. (1992). A crise da sociedade e da educação. Revista Apontamentos, (9), 1-13.

Nagle, J. (1976). Educação e sociedade na primeira república. Rio de Janeiro: EPU.

Neves, M. S. (2003). Os cenários da República: O Brasil na virada do século XIX para o século XX. In L. A. N. Delgado, \& J. L. Ferreira (Orgs.), O Brasil Republicano: $O$ tempo do liberalismo excludente (Vol. 1, pp. 14-44). Rio de Janeiro: Civilização Brasileira.

Patto, M. H. S. (1997). Para uma crítica da razão psicométrica. Psicologia USP, 8(1), 47-62. doi:10.1590/S0103-65641997000100004.

Patto, M. H. S. (1999). A produção do fracasso escolar: histórias de submissão e rebeldia. São Paulo: T. A. Queiroz.

Penna, B. (1997). Por que se impõe a primazia da educação higiênica escolar. In M. J. F. F. Costa, D. R. Shena, \& M. A. Schmidt (Org.), I Conferência Nacional de Educação (1927) (pp. 29-33). Brasília, DF: Inep. (Obra original publicada em 1927).

Piéron, H. (1931). O desenvolvimento mental e a intelligencia: Resenhas e Analyses. Archivos Brasileiros de Hygiene Mental, 4(1), 65-68. Recuperado de http://old.ppi.uem.br/gephe/index.php/arquivos-digitalizados/14-sample-dataarticles/85-arquivos-brasileiros-de-higiene-mental 
Proença, M. (2004). A queixa escolar e o predomínio de uma visão de mundo. In M. Proença, \& A. M. Machado (Orgs.), Psicologia escolar: Em busca de novos rumos (pp. 19-35). São Paulo: Casa do Psicólogo.

Radecki, W. (1925). Hygiene mental da criança: baseada sobre as leis da psicologia. Trabalhos originaes. Archivos Brasileiros de Hygiene Mental, 1(1), 11-89. Recuperado de http://old.ppi.uem.br/gephe/index.php/arquivos-digitalizados/14-sample-dataarticles/85-arquivos-brasileiros-de-higiene-mental

Reis, J. R. F. (1994). Higiene mental e eugenia: o projeto de regeneração nacional da LigaBrasileira de Higiene Mental (1920-30) (Dissertação de Mestrado em História). Instituto de Filosofia e Ciências Humanas, Unicamp, Campinas, São Paulo, Brasil. Recuperado de http://repositorio.unicamp.br/jspui/handle/REPOSIP/281180

Roxo, H. (1925). Hygiene mental. Archivos Brasileiros de Hygiene Mental, 1(2), 2-9. Recuperado de http://old.ppi.uem.br/gephe/index.php/arquivos-digitalizados/14sample-data-articles/85-arquivos-brasileiros-de-higiene-mental

Santos, B. S. (2006). A construção intercultural da igualdade e da diferença. In B. S. Santos (Org.), A gramática do tempo (pp. 279-316). São Paulo: Cortez.

Schwarcz, L. K. M. (1993). O espetáculo das raças: Cientistas, instituições e questão racial no Brasil: 1870-1930. São Paulo: Companhia das Letras.

Veríssimo, J. (1985). A educação nacional (2a ed.). Rio de Janeiro: Livraria Francisco Alves.

\section{Endereço para correspondência}

Roselania Francisconi Borges

Rua Araxá, 974, Jardim Alvorada, Maringá - PR, Brasil. CEP 87033-190

Endereço eletrônico: roselaniafborges@uol.com.br

Recebido em: 04/06/2018

Reformulado em: 21/10/2019

Aceito em: 10/11/2019

\footnotetext{
Notas

* Psicóloga. Mestre em Fundamentos da Educação (UEM). Doutora em Psicologia e Sociedade (UNESP). Pósdoutora em Psicologia (UEM).

${ }^{1}$ Mantida por meio de contribuições de filantropos e com uma subvenção do governo federal, a LBHM tinha como fundamento básico a elaboração de programas de higiene mental difundidos principalmente através do sistema educacional, visando “...realizar na vida social um programa de higiene mental e de eugenética, que melhore o nível de saúde mental coletiva” (Lopes, 1925, p. 151).
} 
${ }^{2}$ Costa (2004, p. 36) se refere aos higienistas como "[...] profissionais da medicina que funcionaram como teóricos ou executores da política de higienização das cidades, da população e da família”.

3 Após 1926, passaram a ser inseridas algumas concepções de prevenção dirigidas ao público em geral e "daquele momento em diante, o alvo de cuidados dos psiquiatras [higienistas] passou a ser o indivíduo normal e não o doente. O que interessava era a prevenção e não a cura" [grifo nosso] (Costa, 1989, p. 78-79).

4 As edições completas dos Archivos Brasileiros de Hygiene Mental podem ser consultadas em http://www.ppi.uem.br/gephe/.

${ }^{5}$ Criado em 2004, pelo advogado Miguel Nagib e apresentado em 2014 pelo deputado Flavio Bolsonaro (PSLSP), o projeto prevê a garantia do pluralismo de ideias no ensino e a necessidade de evitar que os docentes prejudiquem os estudantes em razão de suas convicções políticas, ideológicas, morais ou religiosas. Recuperado de: http://educacaointegral.org.br/reportagens/por-que-o-escola-sem-partido-vai-contra-o-papel-da-escola/, em 30 de junho de 2018.

Este artigo de revista Estudos e Pesquisas em Psicologia é licenciado sob uma Licença Creative Commons Atribuição-Não Comercial 3.0 Não Adaptada. 